\title{
The Prolonged Anticonvulsant Action of Taurine on Genetically Determined Seizure-Susceptibility
}

\author{
R. HUXTABLE AND H. LAIRD
}

SUMMARY: A prolonged anticonvulsant action of taurine has been shown in a strain of seizure susceptible rats. The audiogenic rat (AS) has lower intracerebral electroshock thresholds in three auditory nuclei; the ventral cochlear, the inferior colliculi and the medial geniculate, and in one nonauditory structure; the reticular formation, than a strain of nonaudiogenic rats (NAS). Furthermore, the $A S$ animals routinely display maximal (tonic-clonic) convulsion, regardless of brain structure stimulated, whereas NAS subjects respond with minimal (clonic) convulsions. Within three minutes of intraventricular injection of $8 \mu$ moles, taurine reduces the susceptibility of AS rats to intracerebral electroshock seizures along with attenuation of the severity of the convulsion. The initial elevation in intracerebral electroshock threshold returns to pretreatment value at 24 hours, only to rise again at 48 hours and to remain elevated

RÉSUMÉ: Nous avons démontré une action anticonvulsive prolongée de la taurine chez une espèce de rats susceptibles aux crises épileptiques. Le rat audiogénique (AS) possède un seuil à l'électrochoc intracérébral plus bas dans trois noyaux auditifs (cochléaire ventral, tubercules quadrijumeaux inférieurs et corps genouillés médians) et une structure non auditive (la formation réticulée) qu'une autre race de rats non audiogéniques (NAS). De plus, les animaux $A S$ démontrent de façon habituelle des convulsions maximales (toniques-cloniques) peu importe qu'elle structure cérébrale fut stimulée, tandis que les animaux NAS répondent par des convulsions minimales (cloniques). Dès 3 minutes après l'injection intraven-

From the Departments of Pharmacology and Pharmacology \& Toxicology, University of Arizona, Tucson, Arizona.

Reprint requests to Dr. R. Huxtable, Department of Pharmacology, University of Arizona, Tucson, Arizona, 85724, U.S.A. through day six after injection. In contrast, the severity of convulsions remains attenuated through 24 hours, after which it returns to pre-injection level. By comparison, NAS animals injected intracerebroventricularly in an identical fashion to the AS rats showed no changes in either seizure threshold or severity of convulsion. The direct injection of $200 n-$ moles of taurine in the inferior colliculi of AS rats produced a slow developing, but prolonged, elevation of intracerebral electroshock threshold of this auditory nuclei. However, at no time after the intracerebral injection of taurine was convulsive severity changed. Injection of taurine into the inferior colliculi of NAS subjects did not change either susceptibility or severity of intracerebral electroshock seizures. The data indicate that taurine produces an anticonvulsant effect which is slow in onset, potent, selective and prolonged.

triculaire de 84 moles, la taurine réduit la susceptibilité des rats AS aux crises post électrochoc intracérébral et atténue la sévérité des convalsions. L'élévation initiale du seuil retourne à des valeurs pré-traitement à 24 heures pour ré-augmenter à 48 heures et demeurer élevée un autre 6 jours après l'injection. Par contre la sévérité des convulsions reste atténuée 24 heures et retourne ensuite au niveau pré-injection. Les animaux NAS après traitement semblable ne montrent aucune modification du seuil ou de la sévérité des convulsions. $L$ 'injection directe de $200 n$ moles de taurine dans le subercule quadrijumeau inférieur de rats $A S$ produit une élévation lente à se développer, mais prolongée, du

(Please turn to page 220)

\section{INTRODUCTION}

Taurine is a $\beta$-amino acid present in high concentrations in the central nervous system. It has many of the characteristics of an inhibitory neurotransmitter or neuromodulator, and has a depressant effect on neuronal firing (Krnjevic and Puil, 1976). Interest has been aroused by the anticonvulsant actions of taurine in various types of experimental epilepsies, and a number of clinical studies have resulted (Van Gelder et al., 1975; Bergamini et al., 1974; Barbeau and Donaldson, 1974; Takahashi and Nakane, 1977).

The mechanism of action of taurine is poorly understood. There is some evidence, however, that taurine acts as an anticonvulsant by rectifying abnormally low glutamate concentrations in epileptic foci (Van Gelder, 1976). No suggestion has been made as to how this is achieved.

The majority of investigations have utilized experimental models of epilepsy obtained by placing cobalt powder (Van Gelder, 1972; Joseph and Emson, 1976), penicillin (Mutani et al., 1971), ouabain (Izumi et al., 1973) or other agents on or into various portions of the brain. These models, therefore, involve focal lesions, from which spontaneous seizures are elicited, beyond the control of the experimenter. We have investigated the involvement of taurine in a genetically determined seizure model: the audiogenic rat. This animal is characterized by a high degree of seizure susceptibility to excessive environmental stimuli, such as sound. Seizure susceptibility is lifelong, consistent and easily quantified. As the appropriate stimulus has to be given before the animal convulses, seizures are under the control of the experimenter. 
Taurine has been shown to have anti-convulsant activity in the audiogenic rat, the severity of seizures being reduced (Laird and Huxtable, 1976). We report further studies on the mechanism of action of taurine in this animal. Seizures elicited by the application of electric current to discrete brain regions have been used instead of sound-induced seizures. Alterations in the threshold current are a more sensitive and more readily quantified index of seizure susceptibility.

\section{METHODS AND MATERIALS}

Male audiogenic seizure susceptible Sprague-Dawley (AS) rats from the University of Arizona colony and non-audiogenic Sprague-Dawley (NAS) rats (Holtzman Company) weighing between 290 and $340 \mathrm{~g}$ were screened for response to the audiogenic stimuli. Only AS rats that exhibited a maximal convulsive pattern and NAS animals that showed no seizure response to sound stimuli were used in these experiments. Such animals were randomly divided into appropriate test and control groups.

\section{Surgical Preparation of Animals Cannulae andlor Electrode Implan- tation}

Groups of AS and NAS subjects were bilaterally implanted with bipolar stimulating electrodes (twisted teflon coated stainless steel wire) in one of the following brain structures: the ventral cochlear nuclei, the inferior colliculi, the medial geniculate bodies or the reticular formation. These subjects were used for bilateral determinations of intracerebral electroshock thresholds (IET).

Other groups of AS and NAS animals were prepared for intracerebroventricular drug administration by the implantation of a cannula into the right lateral ventricle, as previously described (Laird and Huxtable, 1976). Some of these cannulated AS subjects were used for studying the action of selected inhibitory amino acids on audiogenic seizure severity. The remaining cannulated subjects were bilaterally implanted with bipolar stimulating electrodes in the inferior colliculi. These animals were used for the study of the action of intracerebroventricularly injected taurine on inferior colliculi IET values.

Lastly, groups of AS and NAS rats were bilaterally implanted with electrode-cannula units into the inferior colliculi. The electrodecannula unit fashioned from 23 gauge stainless steel needles around which is twisted two lengths of 30 gauge teflon-coated stainless steel wire permits the determination of IET values in the inferior colliculi and the injection of taurine directly into the nuclei.

All animals were individually housed immediately following surgery and for the duration of the experiments. The animals were quartered in a controlled soundattenuated environment of $27^{\circ} \pm 5^{\circ} \mathrm{C}$ with a 12 hour light-dark cycle and with free access to food and water.

Stereotaxic coordinates for each brain site were obtained from the atlas of the rat brain by Pellegrino and Cushman (1967) and electrode and cannula placements were histologically verified in each animal.

\section{Experimental Methods \\ and Procedures}

One week after surgery, the groups of AS rats cannulated in the right lateral ventricle were tested for response to the audiogenic stimuli as previously described (Laird and Huxtable, 1976). Each animal was scored for audiogenic seizure severity by the scoring system developed in our laboratory (Jobe et al., 1973). The audiogenic response score (ARS) ranges from zero (no response) to 9 (maximal response). All animals selected for this study had ARS values $>5$.

In a similar manner, one week following surgery, the remaining groups of AS and NAS animals were tested for IET. For this procedure the subject was connected from the amphenol cap (plug) affixed to its skull to an eight strand shielded EEG cable which was attached to a mercury swivel connector (Technical Concepts, Bronx. New York) mounted in the top of the testing chamber. The output from the mercury connector was fed via shielded cables to a sine-wave stimulator (model 82408, Lafayette Instrument Co., Lafayette, Indiana).

We defined the IET as the minimum current, in $\mu \mathrm{A}$, required to elicit consistently a convulsion. IET values were determined on each side of a given structure by administration of graded intensities of electrical current as $60 \mathrm{~Hz}$ sine-wave pulses of 5 seconds duration. Animals were tested daily on alternate sides until stable thresholds were obtained. All threshold testing and taurine injections were made during the same time period each day (0800 - 1200 hours). Regardless of treatment, each animal was tested for IET no more frequently than once every 24 hours.

Following IET determinations in the inferior colliculi, groups of AS and NAS rats were injected with taurine or an osmotically equivalent dose of saline into either the lateral cerebral ventricle or directly into the inferior colliculi. Taurine, $8 \mu$ moles in a volume of $20 \mu \mathrm{l}$, or saline (4 $\mu$ moles in $20 \mu$ l) was injected, over a 3 minute period, into the right lateral cerebral ventricle and the IET value determined 3 minutes after injection on the side previously showing the lower IET value.

In the other experiments, taurine $(200 \mathrm{nmoles}$ in a volume of $0.5 \mu \mathrm{l})$ or saline (100nmoles in a volume of $0.5 \mu \mathrm{l})$ were directly injected into the inferior colliculi and IET values determined periodically after injection.

Electroshock seizure severity was ranked according to the number of running episodes and convulsive pattern exhibited by the animal. For example, the intracerebral electroshock seizure pattern routinely observed under our experimental conditions is a very short, wild running episode, initiated 1 to 2 seconds after electrical stimulation has begun, terminated by a convulsion. The convulsive patterns displayed by the animal may range from a minimal (i.e., generalized clonus of forelimbs, hindlimbs, pinnae and/or vibrissae usually forelimbs are maintained in a clonic extension with the neck dorsiflexed) to a maximal (i.e., tonic flexion of neck, trunk and forelimbs and tonic hindlimb extension). 


\section{Statistical Analyses}

Intracerebral

electroshock threshold values were either compared as actual values (i.e., changes in $\mu \mathrm{A}$ ) or percentage changes over control values with each animal used as its own control. All means were tested for significance by a paired ' $t$ ' test (Steel and Torrie, 1960).

\section{RESULTS}

Response to Intracerebral Electroshock: Thresholds and

Seizure Patterns in AS and NAS Rats

Table 1 compares IET values in three auditory nuclei and one nonauditory structure, the reticular formation in AS NAS rats. The AS animals have uniformly lower IET in all brain regions examined. In addition to the differences in IET values, IET values observed between the two strains also show differences in the type of convulsions produced by focal electroshock in AS and NAS animals. The AS subjects have maximal convulsions (i.e., tonic flexion of neck, trunk and forelimbs and hindlimb extension) regardless of

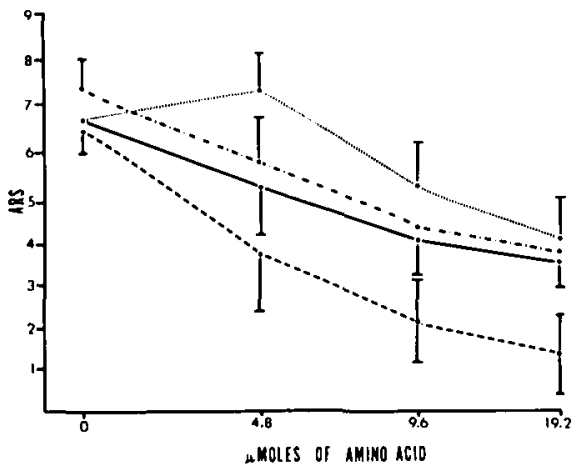

Figure 1-Effect of intracerebroventricularly injected taurine (- - $),$ GABA $(-)$, glycine $(--)$, and aminoisobutyric acid (-.-) on soundinduced seizures. The audiogenic response score (ARS) is plotted on the ordinate. Each point represents the mean \pm the standard error for six animals. All doses of taurine $(4.8,9.6$ and $19.2 u$ mole) caused a significant ( $p$ $<.01)$ reduction in ARS compared to the saline injected control. GABA and glycine significantly reduced ARS at doses of 9.6 and $19.2 \mu$ mole ( $p<.05$ ). A significant decrease in ARS was seen only at the highest dose of aminoisobutyric acid employed. the brain region stimulated (i.e., auditory or nonauditory), whereas the NAS rats always display a minimal convulsion (i.e., generalized clonus of the forelimbs, hindlimbs, pinnae and/or vibrassae-in some cases the forelimbs are maintained in clonic extension with the neck dorsiflexed). Furthermore, the seizure activity produced in AS and NAS subjects by focal electrical stimulation of the auditory nuclei were similar to those elicited by sound in the AS rat (i.e., violent running which terminates in tonic-clonic convulsion and postictal depression). In contrast, the electrical stimulation of the reticular formation in AS and NAS rats did not produce the wild running response observed after stimulation of auditory nuclei, even though behavioral convulsions could, in some cases, be produced.

\section{Effect of Taurine}

\section{Given Intraventricularly}

Figure 1 shows the anticonvulsant efficacies of four amino acids; taurine, gamma aminobutyric acid (GABA), glycine and amino-isobutyric against sound-induced seizures following intraventricular injection. These amino acids exerted a dosedependent reduction in audiogenic anticonvulsant action seizure severity against audiogenic seizures, with the order of potency being taurine $>$ GABA $=$ glycine $>$ amino-isobutyric acid. In addition to the anticonvulsant effect of these amino acids, at higher doses there was an accompanying behavioral depression (i.e., a decrease in locomotor activity and ataxia). However, the lowest dose of taurine, $4.8 \mu$ moles, produced a $31 \%$ reduction in seizure severity, without overt signs of behavioral depression.

\section{TABLE 1}

Intracerebral Electroshock Thresholds of Auditory and Non-Auditory Regions of the Brains of Audiogenic ( $A S)$ and Non-audiogenic (NAS) Rats

Intracerebral Electroshock Thresholds $(\mu \mathrm{A})$

Brain Region

$\begin{array}{llll}\text { Inferior } & \text { Medial } & \text { Ventral } & \text { Reticular } \\ \text { Colliculi } & \text { Geniculate Body } & \text { Cochlear Nucled } & \text { Formation }\end{array}$

Left Side

\begin{tabular}{|c|c|c|c|c|}
\hline \multirow[t]{2}{*}{ AS } & $42.9(14) * *$ & $73.3(3) * *$ & $47.5(4) * *$ & $80.0(3)$ * \\
\hline & \pm 7.2 & \pm 13.6 & \pm 8.8 & \pm 11.6 \\
\hline \multirow[t]{2}{*}{ NAS } & $184.2(12)$ & $400(3)$ & $>1000(4)$ & $190(2)$ \\
\hline & \pm 39.5 & \pm 38.5 & & \pm 10 \\
\hline
\end{tabular}

Right Side

\begin{tabular}{|c|c|c|c|c|}
\hline \multirow[t]{2}{*}{ AS } & $48.9(14) \star$ & $111.7(3) *$ & $42.5(4) \star \star$ & $110.3(3)$ \\
\hline & \pm 7.2 & \pm 47.8 & \pm 7.8 & \pm 17.3 \\
\hline is & $192.9(12)$ & $525.9(3)$ & $>1000(4)$ & $187.5(2)$ \\
\hline & \pm 45.6 & \pm 23.6 & & \pm 7.5 \\
\hline
\end{tabular}

Intracerebral Electroshock thresholds are in terms of $\mu \mathrm{A}$ required to cause a convulsion. Each animal was implanted bilaterally in a selected brain site with bipolar electrodes.

* Significantly different from same brain region in NAS rats, $p<0.01$.

** Significantly different from same brain region in NAS rats, $p<0.001$ 


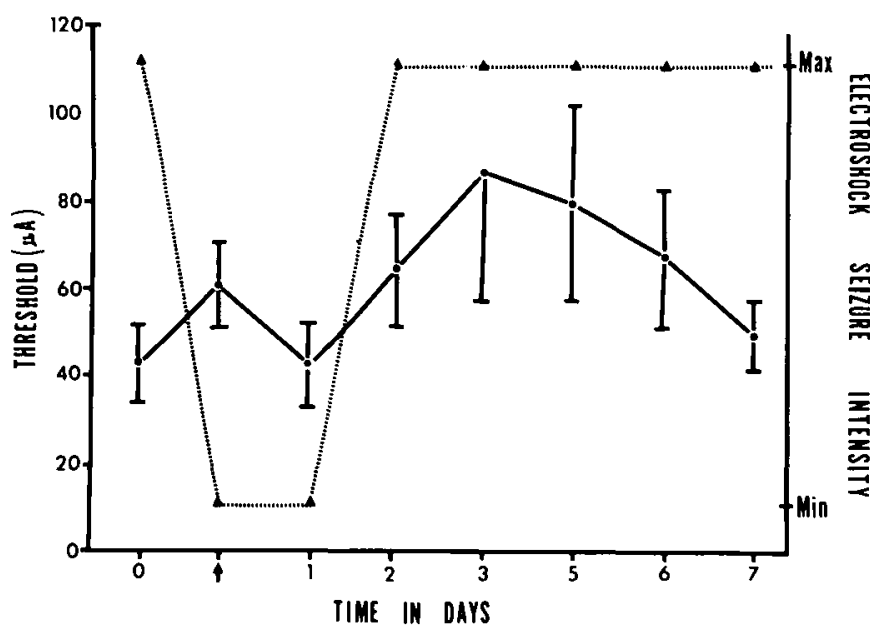

Figure $2 a$-The time course of the effect of taurine (icv) on intracerebral electroshock thresholds of the inferior colliculus and electroshock seizure intensity of audiogenic seizure susceptible rats. The abscissa gives time in days with 0 $=$ control values and $4=3$ minutes after injection. The left ordinate gives intracerebral electroshock thresholds (IET) in $\mu \mathrm{A}$ of the inferior colliculi while the right ordinate gives seizure intensity (the type of seizure displayed by the animal). Changes in threshold are represented by the solid line. The dotted line shows changes in seizure intensity. Each point is the mean \pm standard error of 3 animals. The 3 min. 2, 3, 4, 5, and 6 day changes in IET are significantly $(\mathrm{p}<.05)$ different from control (0) IET.

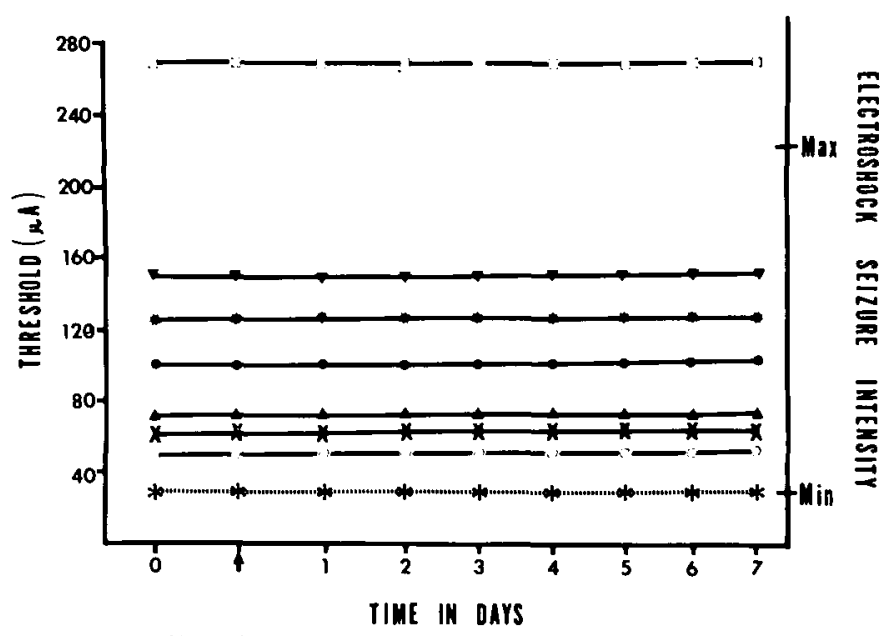

Figure $2 b$-The time course of the effect of taurine (icv) on IET of the inferior colliculi and electroshock seizure intensity of NAS rats. The abscissa gives time in days with $0=$ control values and $4=3$ minutes after injection. The left ordinate shows IET in $\mu \mathrm{A}$ of the inferior colliculi while the right ordinate shows the seizure intensity. The IET value for each subject is plotted (solid lines) across the time course of the experiment. Electroshock seizure intensity is shown for the group with each point representing the response of 6 animals. Since all animals responded in the same manner (all displayed clonic convulsions with one running episode) there are no deviations from the mean.

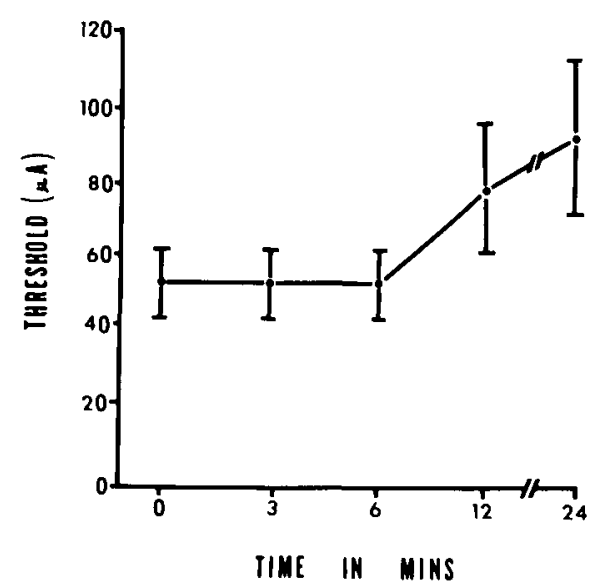

Figure 3-Time course for onset of anticonvulsant effect of taurine after injection into the inferior colliculi of AS rats. The abscissa shows time in minutes after bilateral injection, except for the final point, which is $24 \mathrm{hr}$. post-injection. The ordinate shows IET in $\mu \mathrm{A}$. Each point shows the mean \pm standard error for 10 animals. IET values at 12 minutes and $24 \mathrm{hr}$. are significantly different from control IET $(\mathrm{p}<.05)$.
This indicates that the anticonvulsant and general depressant actions of taurine, but not of GABA, glycine or amino-isobutyric acid, could be separated. The attenuation of audiogenic seizures by taurine occurs within 3 minutes.

Figure 2a shows the time course of effect of $8 \mu$ moles of taurine injected intracerebroventricularly on inferior colliculi IET values and electroshock seizure intensity. The IET response is biphasic. An elevation of IET in the inferior colliculi is seen at 3 minutes. However, after 24 hours, the IET values have returned to control level, only to rise again at 48 hours, and to stay elevated for 6 days. Further, the severity of the electrically-induced seizures in AS subjects is attenuated within $3 \mathrm{mi}$ nutes of injecting taurine. In other words, the convulsions elicited are less severe; going from maximal to minimal (equivalent to the reduction of the ARS from 9 to 3 ). Decreased seizure severity persists for 24 hours.

By comparison, AS subjects injected with saline in place of taurine showed no change in IET values or seizure severity at any time after injection. Similarly, figure $2 b$ shows that even though there is a wide range in inferior colliculi IET values between NAS subjects there is no variability in IET within a given animal after intracerebroventricular taurine treatment. Furthermore, the convulsive seizure pattern displayed by the NAS rats was not, at any time, altered by taurine treatment (i.e., remained a minimal convulsion equivalent to an ARS of 3). In addition, at no time did we observe behavioral depression in the NAS animals after intraventricular injection of taurine at concentrations which consistently produce depression in AS subjects.

The regional distribution of the radiolabeled inhibitory amino acids taurine, GABA, and of the transportable but non-metabolizable amino acid, amino-isobutyric acid, were determined by injecting 3 groups of AS subjects with $4.8 \mu$ moles of the labeled amino acids. Animals were sacrificed 3 minutes after injection. Each brain was dissected into 7 regions, the frontal cortex, auditory cor- 


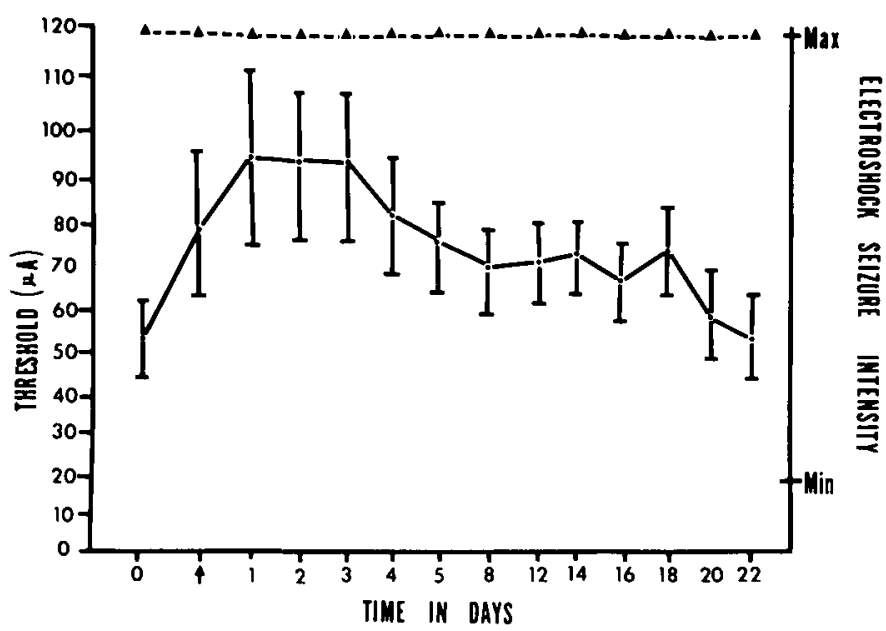

Figure 4a-Time course of anticonvulsant effect of taurine after bilateral injection into the inferior colliculi of AS rats. Each animal was bilaterally injected with 200 nmole taurine in a volume of $0.5 \mu \mathrm{l}$. The abscissa shows time in days with 0 $=$ control values and $\phi=12$ minutes after taurine injection. Left ordinate shows IET (solid line) for the inferior colliculi of AS animals. Each point on this line represents the mean \pm standard error of 10 animals. The right ordinate shows electroshock seizure intensity (dotted line). Each point represents the mean response of 10 animals. Since all animals responded to electrical stimulation with the same type of convulsive pattern (i.e., tonic-clonic) there are no deviations from the mean. All AS animals showed a significant $(\mathrm{p}<.05)$ elevation of IET compared to control after taurine injection from 12 minutes through day 18 .

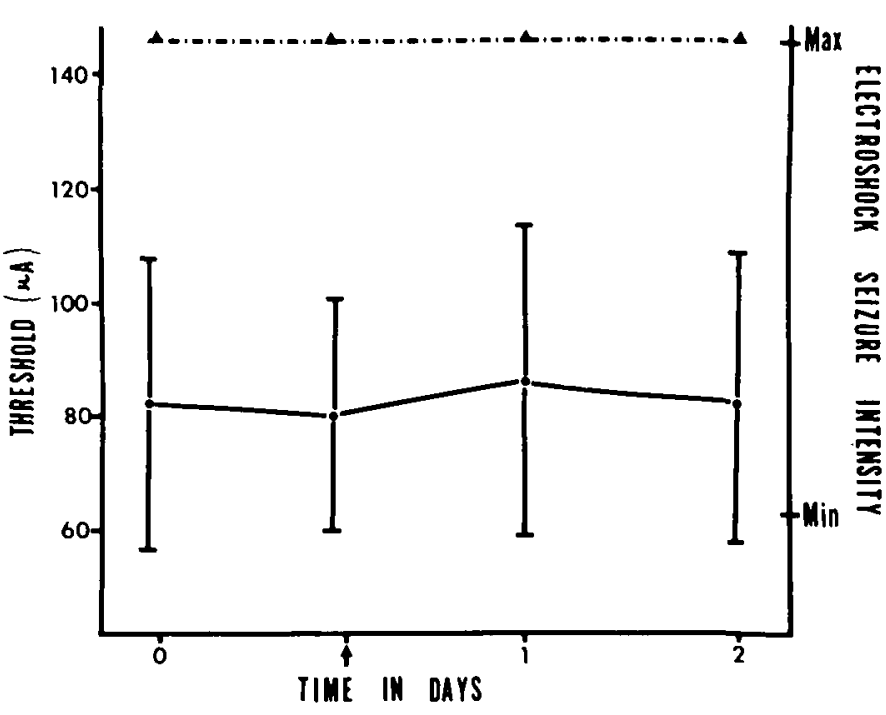

Figure $4 b$-Time course of the effect of saline on IET and electroshock seizure intensity after bilateral injection into the inferior colliculi of ARS rats. Each animal was bilaterally injected with $100 \mathrm{nmole} \mathrm{NaCl}$ in a volume of $0.5 \mu$ !. The abscissa shows time in days with $0=$ control values and $4=12$ minutes after saline injection. The left ordinate shows IET (solid line) with each point being the mean \pm standard error of four animals. The right ordinate shows the electroshock seizure intensity (dotted line) with each point representing response of four animals. Since all animals responded to electrical stimulation with the same type of convulsive pattern (i.e., tonic-clonic) there is no deviation from the mean. None of the IET values after saline injection were significantly different from control values. tex, midbrain, hypothalamus, inferior colliculi, pons-medulla and cerebellum. By determining the uptake of the labeled amino acids into each of these structures we calculated the concentration of amino acid reaching this site within 3 minutes of intracerebroventricular injection. Thus, 200nmoles of taurine had reached the inferior colliculi within 3 minutes. In addition, we observed that there was an appreciably greater uptake of taurine into all parts of the brain (10\% of the activity injected remaining) compared to aminoisobutyric acid and GABA (7\% and $1 \%$ respectively).

\section{Effect of Taurine Injected into the Inferior Colliculi}

As shown in Fig. 3, the bilateral injection of taurine (200nmoles) directly into the inferior colliculi of AS rats had no effect on the IET after 3 minutes. However, taurine did cause a slow developing elevation in IET, reaching a maximum effect 24 hours after injection. Furthermore, the taurine action was of long duration (Fig. 4a), IET values remaining elevated for 18 days. In contrast, injection with 100 nmoles saline (i.e., isoosmotic with the taurine injection) did not produce any change in IET (Fig. 4b). Although there was a marked elevation in IET in AS rats, the taurine injected into the inferior colliculi did not alter the electricallyinduced seizure severity at any time over the 22 day period. Each AS subject continued to display a maximal $(A R S=9)$ convulsion.

In comparison to the effect of taurine on IET values in the inferior colliculi of AS animals, the identical dose of taurine caused no change in IET in NAS rats at any time following injection (Fig. 5).. Further, there was no change in seizure severity in the NAS subjects after injection of taurine into the inferior collucili. The animals continued to display a mini- mal convulsion which was equivalent to an audiogenic response of 3 .

The differences in response of AS and NAS rats to focal electroshock seizures may be summarized as follows:

(1) Electrical stimulation of auditory nuclei in AS and NAS rats produces a seizure response identical to that seen in AS rats as a result of sound stimulation.

(2) AS rats have uniformly lower IET values in all brain structures examined.

(3) Electrically-induced seizures in AS rats are consistently more severe.

These experiments imply that the AS rat has an inborn defect in the central nervous system which results in an increased susceptibility to both sound and electrically induced seizures. Furthermore, because of, or in 


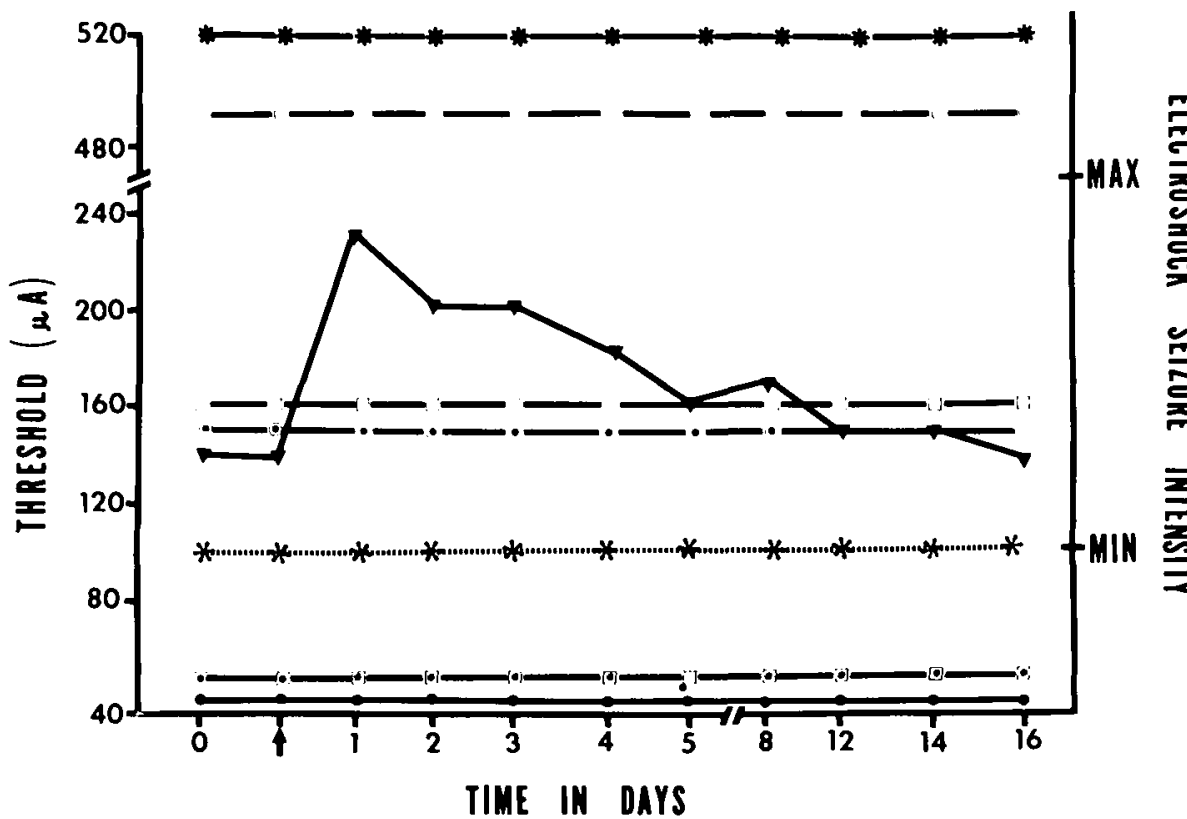

Figure 5-Time course of the effect of taurine on IET and electroshock seizure intensity after bilateral injection into the inferior colliculi of NAS rats. Each animal was bilaterally injected with 200 nmole taurine in a volume of $0.5 \mu$ l. The abscissa shows time in days with $0=$ control values and $t=12$ minutes after taurine injection. Left ordinate shows IET (solid lines) for inferior colliculi of NAS rats. Individual responses of animals are plotted to illustrate the invariance of threshold. The right ordinate shows the electroshock seizure intensity (dotted line) with each point representing the mean of seven animals. As all animals responded to electrical stimulation with the same type of convulsive pattern there is no deviation from the mean. Only one animal ( $\nabla$ ) showed a change in IET relative to the control period.

addition to, being susceptible to sound induced seizures, these animals are more sensitive to maximal electroshock and pentylenetetrazol (Laird and Huxtable, 1978) induced seizures. This suggests a more generalized neuronal defect involving neurons outside of the auditory system. Finally, since AS rats consistently have more severe convulsions regardless of stimulus, this indicates that once seizure activity begins it spreads more readily and involves the entire central nervous system of the animal.

The bimodal response seen after intracerebroventricular injection of taurine presumably reflects the action of taurine at different sites within the central nervous system. The rapid elevation of seizure threshold and reduced convulsive severity are not attributable to an action of taurine on the inferior colliculi since the direct injection of 200 nmoles of taurine on the inferior colliculi had no immediate effect on either electroshock threshold or seizure sever- ity. Presumably, the rapid effect of taurine is mediated by an action on seizure spread, so that the measured threshold is raised indirectly (i.e., by modification of the response between the site of initiation, the inferior colliculi, and the observed behavior, the convulsive seizure). Effects after 24 hours parallel those seen after direct injection of taurine into the inferior colliculi. However, the duration of the taurine response is much shorter, lasting only six days as compared to the eighteen days observed following injecting taurine into the inferior colliculi. This difference in duration of action might be due to the different distributions of taurine in the inferior colliculi following the two types of injections. This suggests that although equal amounts of taurine may be arriving at the inferior colliculi after both intracerebral routes of administration only the direct route is providing the necessary localization to exert a pharmacological effect on seizure threshold over a prolonged period of time.
In conclusion, we have shown that the AS rat is more susceptible to seizures induced by both sound and electrical stimuli. Furthermore, since this increased seizure susceptibility is genetically determined, the AS model provides an excellent system for investigating the pathology and treatment of epilepsy. Moreover, in experiments using this genetic model we have demonstrated that taurine has a potent, selective and long lasting anticonvulsant action. In fact, our data suggest that taurine modifies the biochemical defect that causes the increased seizure susceptibility in these animals. The mechanism by which taurine is acting is open to speculation at this point. Our data is consistent with a mechanism by which taurine is taken up into neurons and/or glial cells and subsequently released to exert an inhibitory action. However, taurine may be exerting an indirect effect by modifying the enzymes of biosynthesis and metabolism of GABA. Van Gelder (1972) has reported that taurine given to cobalt-epileptic mice causes an increase in cortical glutamic acid decarboxylase activity and a reduction in GABA aminotransferase activity. Both the elevation in glutamic acid decarboxylase and decline in GABA aminotransferase activities would be expected to increase brain GABA concentration and, more importantly, increase the amount of GABA available at the synaptic cleft to exert its inhibitory action.

\section{(Continued from page 215)} seuil aux électrochocs intracérébraux de ce noyau auditif. Cependant, la sévérité des convulsions ne fut jamais modifiée après l'injection intracérébrale de taurine. La même injection, au même site, chez les animaux NAS ne change ni la susceptibilité ni la sévérité des convulsions consécutives à un électrochoc intracérébral. Nos données indiquent donc que la taurine produit un effet anticonvulsif d'apparition lente, mais sélectif, efficace et prolongé.

\section{ACKNOWLEDGEMENT}

This project was supported by USPHS grants HL 19394 and HL 20087. 


\section{REFERENCES}

BERGAMINI, L., MUTANI, R., DE. LSEDINE, M. and DURELLI, L. (1974). First clinical experience on the antiepileptic action of taurine. European Journal of Neurology, 11, 261-269.

IZUMI, K., DONALDSON, J., MINNICH, J. L. and BARBEAU, A. (1973). Ouabaininduced seizures in rats: Suppressive effects of taurine and $\gamma$-amino-butyric acid. Canadian Journal of Physiology and Pharmacology, 51, 885-889.

JOBE, P., PICCHIONI, A. and CHIN, L. (1973). Role of brain norepinephrine in audiogenic seizure in the rat. Journal of pharmacology and Experimental Therapeutics, 184, J-10.

JOSEPH, M. and EMSON, P. (1976). Taurine and cobalt induced epilepsy in the rat: $A$ biochemical and electrocorticographic study. Journal of Neurochemistry, 27, 1495-1501.

KRNJEVIC, K. and PUIL, E. (1976). Electrophysiological studies on actions of taurine. In: Taurine (Huxtable, R. and Barbeau, A., eds.), Raven Press, New York, N.Y., pp. 179-189.

LAIRD, H. and HUXTABLE, R. (1976). Effect of taurine on audiogenic seizure response in rats. In: Taurine, (Huxtable, R. and Barbeau, A., eds.), Raven Press, New York, N.Y., pp. 267-274.

LAIRD, H. and HUXTABLE, R. (1978). Taurine and audiogenic epilepsy. In: Taurine and Neurological Disorders (Barbeau, A. and Huxtable, R., eds.), Raven Press, N.Y., pp. 339-357.

MUTANI, R., BERGAMINI, L., FARIELLO, R. and DELSEDIME, $M$. (1974). Effects of taurine on cortical acute epileptic foci. Brain Research, 70, 170-173.
STEEI., R. and TORRIE.J. (1960). Principles and procedures of statistics. McGraw-Hill Book Company Inc.. New York.

TAKAHASHI, R. and NAKANE, Y. (1978). Clinical trial of taurine in epilepsy. In: Taurine and Neurological Disorders. (Barbeau, A. and Huxtable, R., eds.), Raven Press. New York, N.Y. In Press.

van GEL_DER, N. (1972). Antagonism by taurine of cobalt induced epilepsy in cal and mouse. Brain Research, 47, 157-165.

van GELDER. N. (1976). Rectification of abnormal glutamic acid levels by taurine. In: Taurine. (Huxtable, R. and Barbeau, A.. eds.), Raven Press. New York. N.Y.. pp. 293-302.

van GELDER. N.. SHERWIN. A., SACKS. C. and ANDERMAN, F. (1975). Biochemical observations following administration of taurine to patients with epilepsy. Brain Research, 94, 297-306. 